\title{
THE REACTION TO FIRE TESTS FOR NATURAL THERMAL INSULATION OF HEMP MATERIAL MODIFIED BY FIRE RETARDANT OHNOSTOP SPECIAL
}

\begin{abstract}
The scope of the paper is the experiment focused on testing and evaluating the fire protection of fire retardant modification of combustible material by means of experimental scientific method of the reaction to fire test. We tested the specimens of natural thermal insulation made of hempen fibre provided by the company Profi air color s.r.o. Zilina. These tested specimens were impregnated with retardation technology by soaking in the fire retardant Ohnostop special, provided by the company Bakra s.r.o. Rimavska Sobota. The experiment was performed by two experimental methods - the single-flame source test and the test of limited flame spread with the test devices under laboratory conditions. The main aim of the experiment was the assessment and possible improvement of fire-technical properties of thermal insulation material made of hemp by the application of fire retardant modification.
\end{abstract}

Keywords: Reaction to fire tests, thermal hemp insulation, fire retardant, Ohnostop special.

\section{Introduction}

Fire retardants are chemical impregnating substances which can in chemical, physical or combined way protect and prevent the ignition, slow down the process of combustion and eliminate the inception of fire and conflagration. The principle of the retardation process is the continuation of the specific retardation element to the surface and structure of combustible materials. Fire retardants have the ability to improve the fire-technical characteristics and fire resistance of the impregnated material and they also protect materials and products against direct flame contact, spontaneous combustion, flameless combustion (smouldering) and higher temperatures of fire (see [1]).

Classification of fire retardants depending on the principle of retardation (see [2]):

- fire retardants that release and emit non-combustible gases in the heat interval when the combustible gases are generated by thermal decomposition of the combustible material, which leads to dilution and decompression of concentration of flammable gases and, in this way, their ignition is impeded.

- fire retardants that accumulate heat from the source of heat, which leads to cooling the source of heat and slowing down the combustion process,
- fire retardants that create a protective intumescent foam layer (a few centimetres thick) on the surface of impregnated combustible material. This layer separates the surface of combustible material from the heat source and, simultaneously with the chemical reactions, slows down the combustion process,

- fire retardants that represent the mechanical type (for example, various building films and claddings made of noncombustible materials).

Classification of fire retardants depending on the way of application:

- coating (building constructions, metals),

- impregnation (wood, wood products),

- soaking (plastics, thermal insulation).

We experimentally tested the tangible fire retardant named Ohnostop special invented to decrease the combustibility and to improve the fire resistance of building products in interior spaces. This fire retardant can achieve the class of reaction to fire in accordance with standard EN 13501-1+A1:2010 : B-s1, d0. The Ohnostop special is a colourless watery substance of inorganic salts, $100 \%$ ecological, naturally recyclable, environmental and health friendly (see [3]). The composition of the product:

\footnotetext{
* ${ }^{1}$ Adelaida Fanfarova, ${ }^{2}$ Ladislav Maris, ${ }^{1}$ Anton Osvald, ${ }^{3}$ Esko Mikkola

${ }^{1}$ Department of Fire Engineering, Faculty of Security Engineering, University of Zilina, Slovakia

${ }^{2}$ Department of Security Management, University of Zilina, Slovakia

${ }^{3}$ KK-Palokonsultti Oy, KK-Fire Consult s.r.o., Espoo, Finland

E-mail: Adelaida.Fanfarova@fbi.uniza.sk
} 
ammonium hydrogenorthophosphate technical - $\left(\left(\mathrm{NH}_{4}\right)_{2} \mathrm{HPO}_{4}\right)$, ammonium sulphate technical $\left(\left(\mathrm{NH}_{4}\right)_{2} \mathrm{SO}_{4}\right)$ and water $\left(\mathrm{H}_{2} \mathrm{O}\right)$. Physical and chemical properties : liquid state, transparent colour, odour after urea, completely mixable, the density of 1180 - 1200 $\mathrm{g} / \mathrm{m}^{3}$, a boiling point of $100{ }^{\circ} \mathrm{C}$, the decomposition temperature of $400{ }^{\circ} \mathrm{C}$, flash point is not, is not self-igniting and is not dangerous explosion. It is one of fire retardants that release the non-combustible gases at the same time the combustible gases are produced. During the long-term affecting of open-direct flame this fire retardant prevents the fire spread. We can apply it by soaking, coating, spray application or by the vacuum - pressure method.

The careful choice of a fire retardant, the correct way of application and professional assessment of conditions and environment which will affect combustible material - all of these factors represent the functional and qualitative system of retardation process (see [4]). The mechanism of action of fire retardants usually depends on their chemical properties of material that we want to protect against the negative effects of fire. Fire retardants can be applied to various types of materials, for example, wood, plastics, metals, textiles, furniture, toys, cable bundles, electrical appliances, the construction and design elements, coverings of wall and ceilings, flooring, indoor and outdoor paints, thermal insulation.

Due to environmental aspects, the use of natural insulation materials made of plant materials, namely hempen fibre, is becoming more popular. There are two basic hemp species: Cannabis indica (containing psychoactive substances) which is not used in the construction industry and Cannabis sative (without psychoactive substances) which is used widely in various industries. As a building material, hemp represents a material that is difficult to replace by industrially manufactured insulation products due to its natural and unique properties. In addition, it is also produced from a renewable and sustainable source.

Hemp fibre insulation can be characterized by specific properties such as: high moisture resistance, ability to dry quickly, insulation stability in extreme conditions and creation of natural microclimate. Due to the natural content of bitter substances, it does not support fungal growth and has a certain resistance against rodents. Another advantage of hemp is its short vegetation period (harvesting is possible twice a year) and from a production point of view, fast renewal ( $3 \mathrm{~m}$ growth in 3 months). The hemp insulation materials have good heat- and sound-insulation properties, owing to the sturdiness of the hemp fibres which are sufficiently flexible and can return to the original shape after a short compression. The hemp fibre is also able to maintain its shape and is not prone to material compaction and creation of unwanted cavities in places where insulation is required. Manipulation with this material is without health risks, such as skin damage, eye and airways irritation (see [5]).

Thanks to the above mentioned properties hemp insulation achieves higher qualitative standards in comparison to styrofoam, mineral or glass wool. It is also important to point out that hemp as a pure natural material is environmentally friendly, with no adverse health effects, recyclable and renewable.

\section{Reaction to fire tests}

The experiment consists of two different tests of reaction to fire performed under laboratory conditions:

1. Reaction to fire test - Ignitability of building products subjected to direct impingement of flame, part 2 - the single-flame source test - in accordance with Slovak technical standard STN EN ISO 11925-2: 2011. This method has been developed for determining the reaction of building materials to fire and it specifies the fire test for testing ignitability of combustible materials exposed to direct small flame with zero radiation, using vertically mounted specimens. Although this method is intended for determining the ignitability, it is based on the small flame spread on the vertical specimen surface after the application of small flame (match size) either to the surface or edge of the specimen for a period of 15 or $30 \mathrm{~s}$. The duration of the test begins to elapse after the specimen is exposed to the flame. If the duration of the flame exposure is $30 \mathrm{~s}$, then the entire test duration is $60 \mathrm{~s}$ (see [6]);

2. Reaction to fire test - Methodology for testing the fire retardants and retardant modifications of material - the test of limited flame spread. This method was developed in the Fire-chemical laboratory of the Department of Fire Engineering, Faculty of Security Engineering, University of Zilina as an internal document with the aim of becoming an STN standard. The methodology was created with the purpose of evaluating the specimen combustion behaviour when exposed to a direct mid-height flame for a longer time period. It describes and specifies the fire test for testing retardant treatments of combustible materials exposed to a mid-height flame, with the surface exposure angle of $45^{\circ}$ to the vertical axis (see [7]).
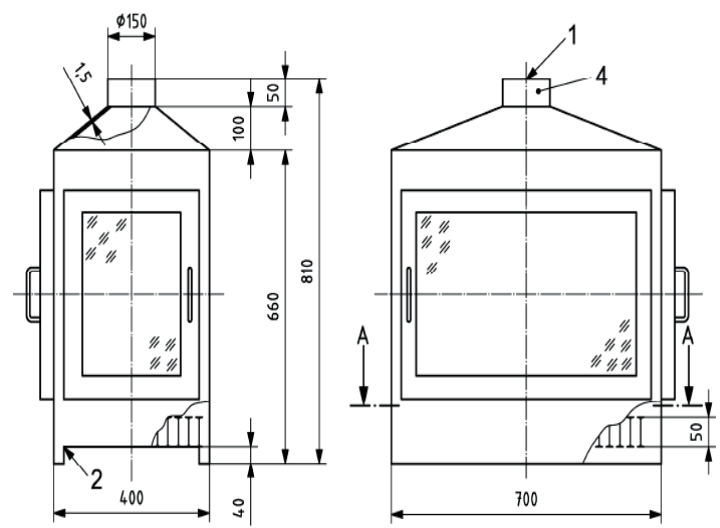

Fig. 1 The scheme of the test device

(1 - measured area of air circulation speed, 2 - metallic grating, 3 - horizontal board, 4 - chimney) (see [6]) 
It is necessary to maintain the ambient temperature of $23{ }^{\circ} \mathrm{C}\left( \pm 5{ }^{\circ} \mathrm{C}\right)$, relative humidity of $50 \%( \pm 20 \%)$ for the correct test procedure. Both test devices are located in such laboratory ambient conditions. A stainless steel combustion chamber with a fire-resistant glass door on the front face and one side is designated for the single-flame source test (see Figs. 1 and 2).

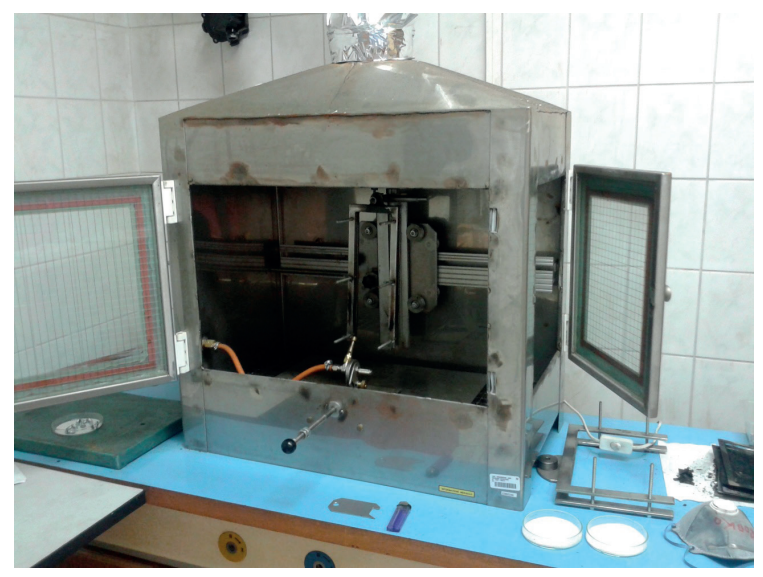

Fig. 2 The test device - combustion chamber located in the fire-chemical laboratory of KPI FBI ZU

The holder for the test specimen consists of two stainless steel U-shaped frames. The frame is fixed to a stand to which the specimen holder is fixed in such a way that it is not suspended too low and its open edge with the test specimen is exposed to the flame of the propane burner. The gas burner as the ignition source is designed for the use in a vertical orientation or under the angle of $45^{\circ}$ (see Figs. 3 and 5). It is equipped with a valve for the exact flame height regulation. The device for flame height measurement is capable of identification of the prescribed flame height of $20 \mathrm{~mm}( \pm 0.1 \mathrm{~mm})$ (see Fig. 4). The height of the flame is measured from the top edge of the burner to the yellow flame top (see Fig. 10). This check must be carried out prior to the test of each specimen, just before the test starts.

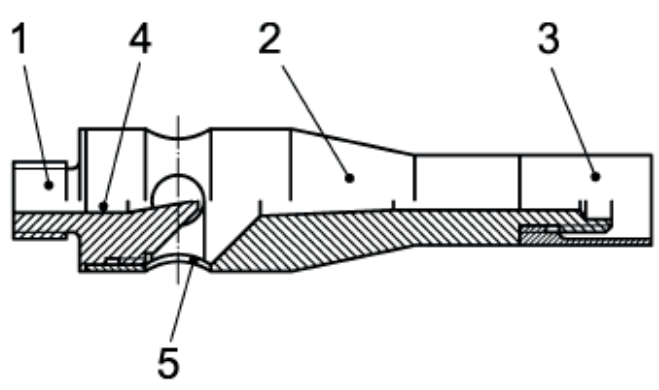

Fig. 3 The scheme of gas burner (1 - gas jet, 2 - pipe, 3 - flame stabilizer, 4 - mixing tube, 5 - construction rabbet) (see [6])

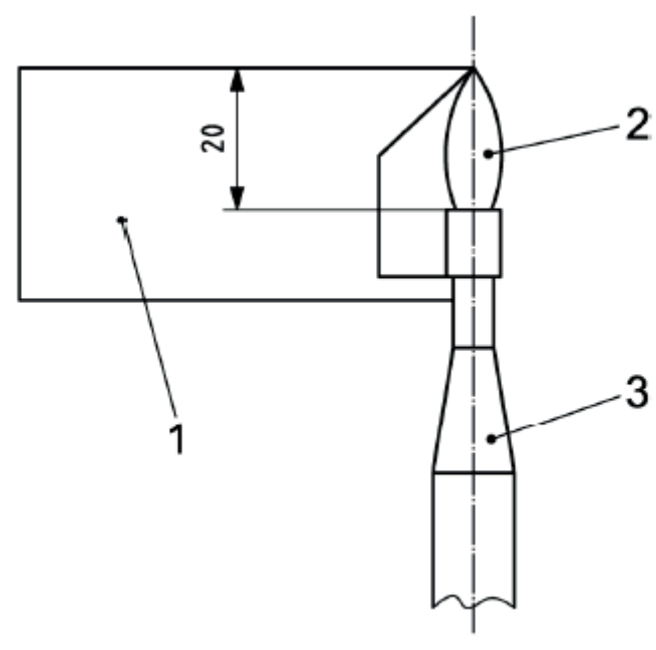

Fig. 4 The equipment for flame height measurement (1 - metallic board, 2 - flame, 3 - gas burner) (see [6])

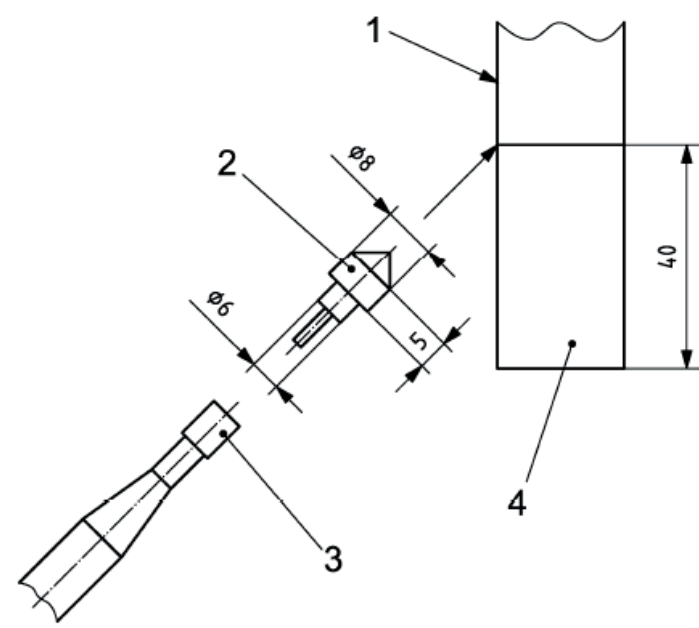

Fig. 5 The scheme of the flame impact on the surface of test specimen (1 - specimen surface, 2 - spacer, 3 - gas burner, 4 - test specimen) (see [6])

The test device for testing the limited flame spread determination is made of materials resistant to heat and combustion products released during the test. This device (see Fig. 7) consists of a test specimen holder of non-combustible material, gas burner, flow meter with fuel flow regulation and the fuel source - technical propane butane mixture cylinder and is constructed according to the scheme (see Fig. 6) adopted from an older standard (STN 730862 - supplement b). The ignition source is the gas burner designed and constructed (see Fig. 3) so that it can be firmly and securely fixed in the test apparatus and is controlled by a valve, ensuring the correct flame height $100 \mathrm{~mm}$ $( \pm 2 \mathrm{~mm})$. 
The fuel source in both tests is a pressure cylinder with a technical propane-butane mixture with purity of at least $95 \%$. Other devices required for the tests are calibrated scales (with a precision of at least two hundreds of a gram) used for mass measurement of the specimens and time measurement devices for the measurement of the flame exposure duration.

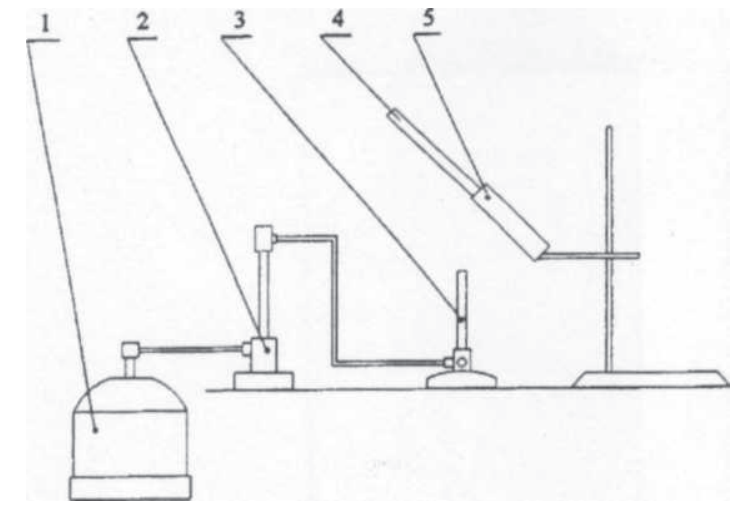

Fig. 6 The scheme of the test device

(1-gas cylinder, 2 - flow meter, 3 - gas burner, 4 - test specimen, 5 holder for the test specimen) (see [7])

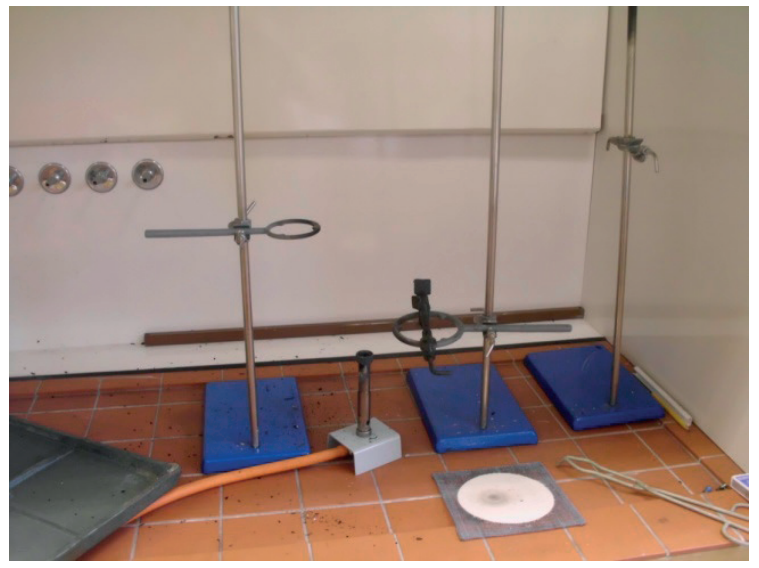

Fig. 7 The test device designed and located in the fire-chemical laboratory of KPI FBI ZU

The tests specimens for the experiment comprised six sets of specimens which were cut from a representative specimen of thermal hemp insulation (see Fig. 8). Each specimen had dimensions of $200 \times 100 \times 40 \mathrm{~mm}( \pm 1 \mathrm{~mm})$. One set of test specimens comprised six specimens of natural material of the above stated dimensions (see Fig. 9).

For both reactions to fire tests three sets of test specimens were prepared:

- the first set of specimens (marked $1 » 6$ ) was impregnated by soaking in the fire retardant Ohnostop special,

- the second set of specimens ( 7 »12) was similarly impregnated by soaking in the fire retardant Ohnostop special but with addition of another effective chemical element in order to increase its fire protection,

- the third set of specimens (X1» X6) was not impregnated in any way and was used as a fire retardant efficacy benchmark.

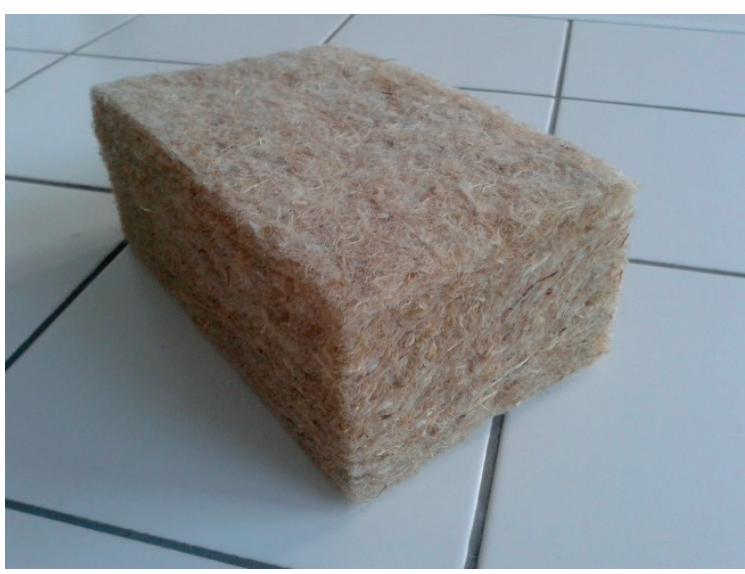

Fig. 8 The representative test specimen of thermal hemp insulation

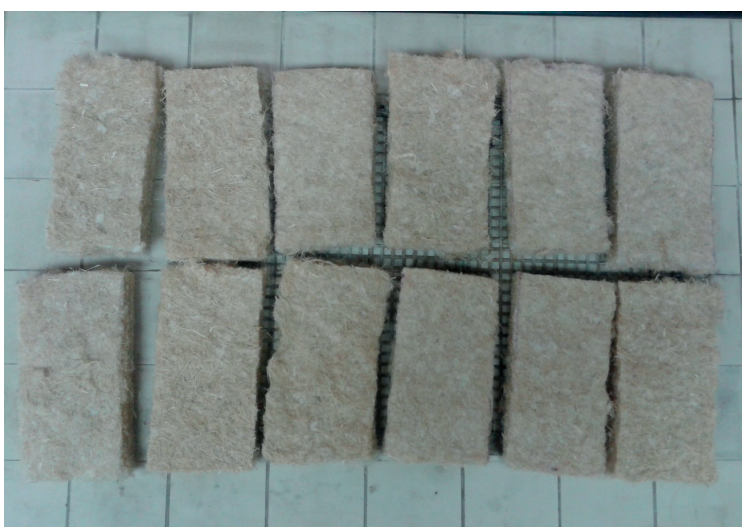

Fig. 9 Two sets of test specimens soaked in the fire retardant

The preparation for both reactions to fire tests included mixing the Ohnostop special fire retardant solutions in compliance with the producer's instructions. The specimens of hemp insulation were impregnated by soaking for 5 minutes, whereas $350 \mathrm{ml}$ of fire retardant solution was used for each two specimens. Subsequently, the specimens were weighed in regular intervals until completely dry, which meant complete evaporation of water bound during the retardation process. When the weight of all test specimens became stable (with $1 \mathrm{~g}$ deviation), the test devices were prepared and the required laboratory conditions arranged. The methodology for the single-flame source test: each test specimen was fixed into the holder which was placed into the test device (see Fig. 10). The burner was lit in the vertical orientation and the flame was left to stabilise for a few minutes to achieve the prescribed height. Subsequently, the gas burner was adjusted 


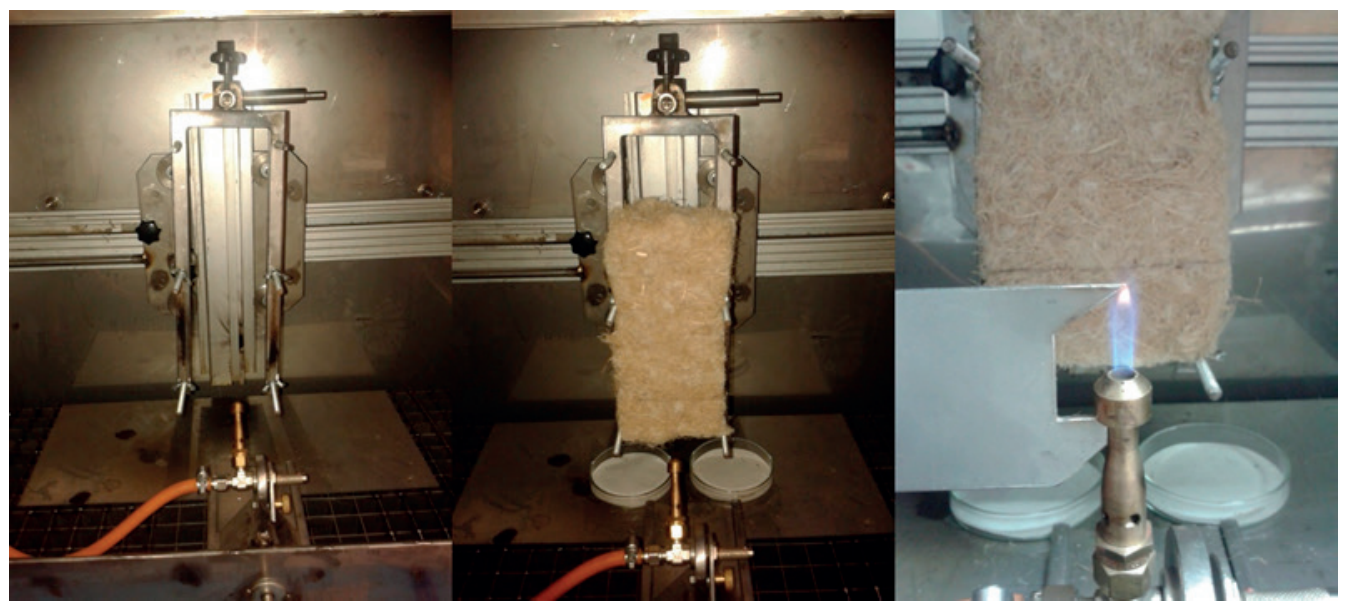

Fig. 10 The holder for the test specimen, consolidation of the test specimen to the holder, flame height measurement (left to right)

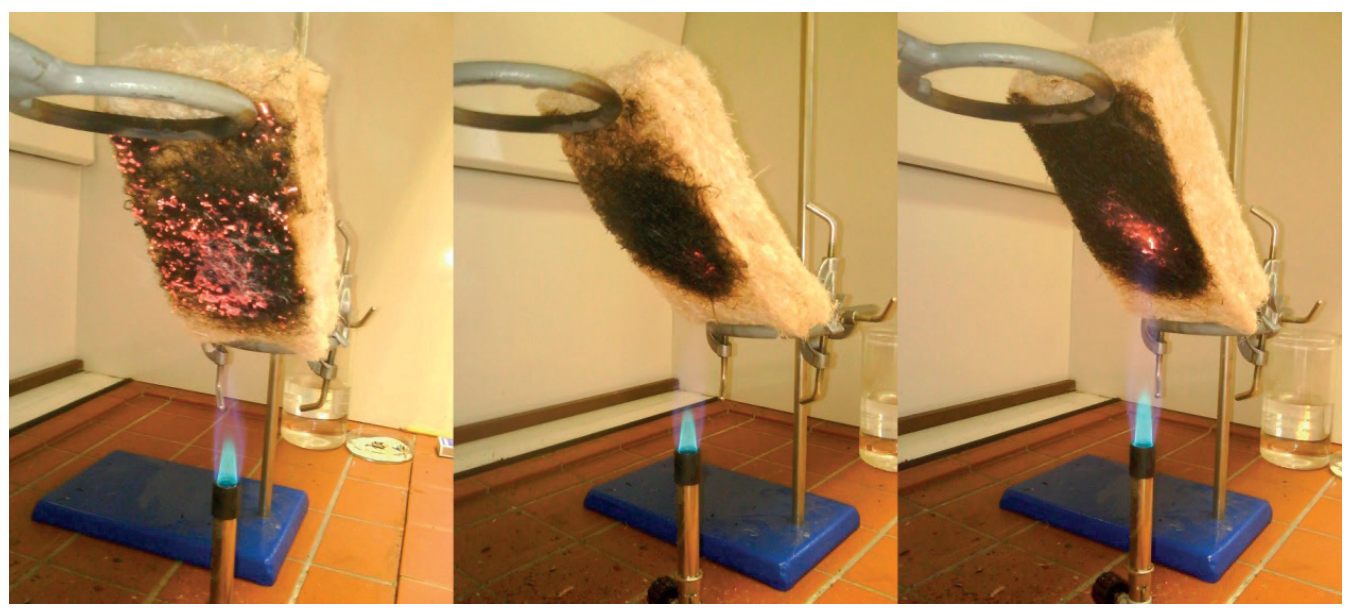

Fig. 11 The test specimen consolidation in holder, flame height measurement, testing (left to right)

to $45^{\circ}$ and was moved horizontally until the point of contact with the specimen ( $40 \mathrm{~mm}$ above bottom edge of specimen) was reached. The duration of the flame exposure was 30 seconds and was measured from the moment of the flame contact with the specimen. The methodology for the test of the limited flame spread: each test specimen was placed in the test device holder under the angle of $45^{\circ}$ and was exposed to the effects of an open mid-height flame for 5 minutes. For each individual test the height of the flame was exactly defined. Similarly, each test adhered to the unified test methodology (see Fig. 11).

\section{The results of reaction to fire tests}

All the test specimens were evaluated by the fire-technical characteristics specified for the process of combustion and fire development (time of ignition, time of spontaneous combustion and time of smoulder). The behaviour of the tested material during the testing procedure was also observed. The results of the tests of reaction to fire are summarized according to the sets of the test specimens as follows:

STN EN ISO 11925-2:2011 - Single-flame source test:

- the first set of the tested specimens soaked in the fire retardant Ohnostop special did not participate in the process of combustion in any way, there was no ignition, no sustained flaming, the test specimens did not spread the flame on the outer surface, there was no smoke, no smouldering, no dripping of flaming debris and no ignition of filter paper,

- the second set of the tested specimens also impregnated with the fire retardant Ohnostop special (but supplemented with one unnamed chemical element to improve the fire-fighting properties and qualities of the fire retardant) behaved in the same way as the first set of the tested specimens,

- the third set of tested specimens which was not modified in any way at all during the testing procedure significantly participated in the process of combustion, the tested specimens were ignited and the material spread the flame on 
the outer surface, there was no sustained flaming, but high time of smouldering, tested specimens smoked visibly, there was no dripping of flaming debris and no ignition of filter paper was observed.

Methodology for testing the fire retardants - The test of limited flame spread:

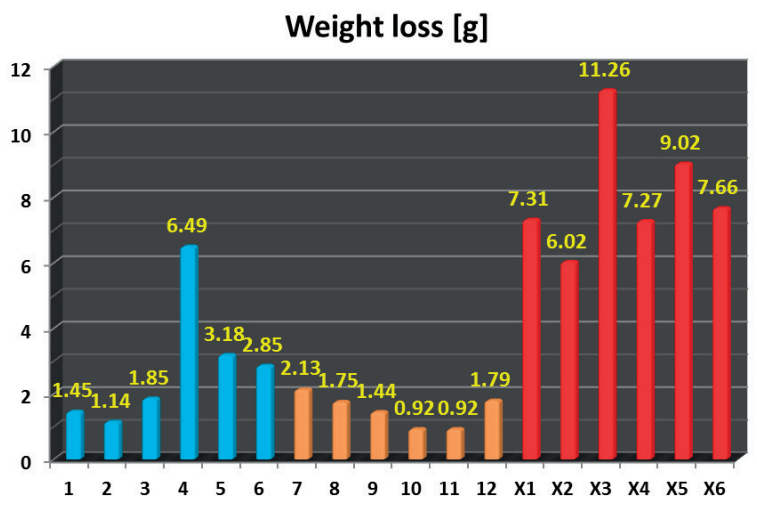

Fig. 12 The graph of values of weight loss of the test specimens

\section{Time of ignition [s]}

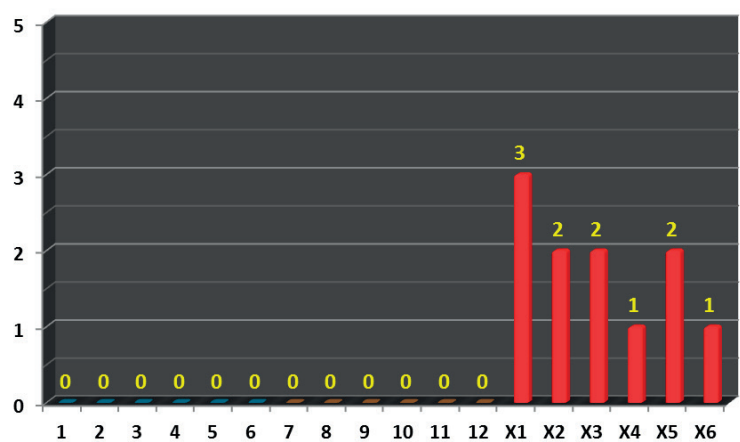

Fig. 13 The graph of values of time of ignition of the test specimens

\section{Time of spontaneous combustion [s]}

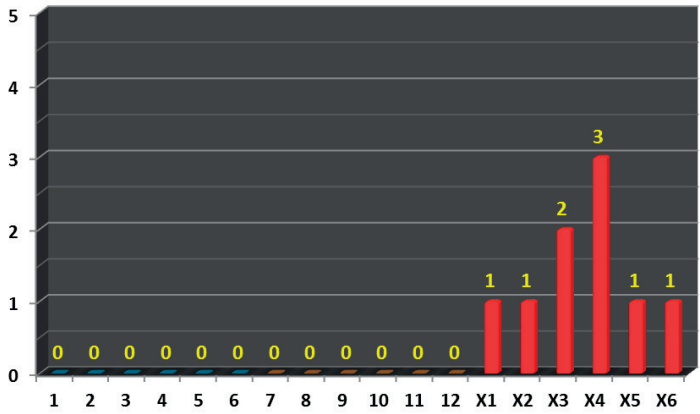

Fig. 14 The graph of values of time of spontaneous combustion of the test specimens

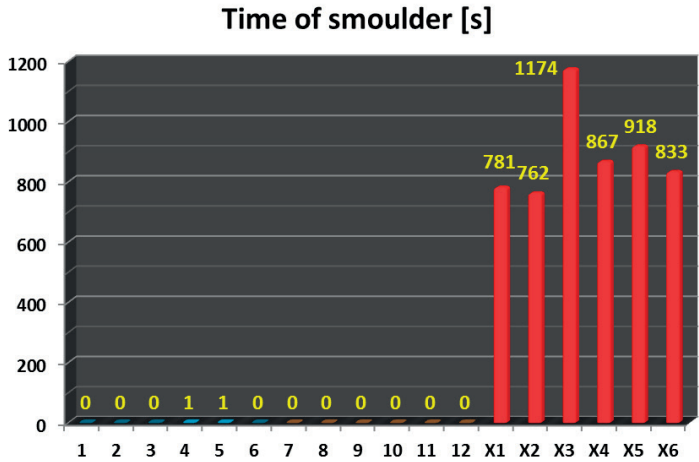

Fig. 15 The graph of values of time of smoulder of the test specimens

\section{Conclusion}

Based on the measured data from both tests of reaction to fire of combustible thermal insulation product made of natural hemp material, it is obvious that to improve the fire-technical characteristics of this material, it is advisable to impregnate it properly with a selected fire retardant. The suitable fire retardant can prevent the thermal hemp insulation to participate actively in the process of combustion. The fire retardant applied in our experiment was apparently able to slow down the combustion process. This phenomenon happens thanks to chemical composition and properly selected way of application of our fire retardant. During the retardation process the individual components of chemical composition strengthened effectively the structure of the combustible material and this slowed down the combustion cycle. All that almost completely eliminated the ignition, spontaneous combustion and smouldering of the tested material during the testing procedure. It is obvious from the above mentioned graphical representations of the results (see Figs. 12 - 15).

In standard practice these findings can be used, for example, in the possible deceleration of complete burnout time in the case of building fire, which can help save human lives, reduce property damages or mitigate negative environmental impacts. The team of authors aim to point out the use of fire retardants in standard practice and underline the importance of fire protection and fire-fighting qualities of retardant modifications of combustible materials and products.

\section{Acknowledgements}

The authors of the paper would like to express their gratitude to Mr. Arpad Krausz, the managing director of company BAKRA s.r. o., producer of the fire retardant OHNOSTOP special and to Mr. Zdeno Duris, the managing director of company PROFI AIR-COLOR, s. r. o., producer of natural thermal insulation made of hempen fibre CANABEST.

Special thanks also belong to FBI ZU for supporting the institutional grant of the project - IGP 201406. 


\section{References}

[1] DRYSDALE, D.: An Introduction to Fire Dynamics. University of Edinburgh, West Sussex : John Wiley \& Sons Ltd., $2^{\text {nd }}$ ed., 1999 , 576 p. ISBN 0471972908.

[2] OSVALD, A.: Evaluation of Fire Safety Materials and Products of Wood. Textbook. Zvolen : Technical university in Zvolen, 1997, 104 p. ISBN 80-228-0595-5.

[3] BAKRA, s. r. o.: Product Ohnostop special. 2013. [on line]. [cit. 2014-09-15]. Available at: http://www.ohnostop.com/ohnostopspecial.html.

[4] MIKKOLA, E.: Fire Retardants and Product Behaviour in Fire Tests. Polymer International. Special Issue: Fire Retardant Polymers, vol. 49, No. 10, pp. 1222-1225, October 2000. Online ISSN: 1097-0126.

[5] PROFIAIRCOLOR, s. r. o.: Natural Thermal Insulation Materials. 2014. [on line]. [cit. 2014-09-15]. Available at: http://www. proficolor.sk/drevostavby8.html.

[6] STN EN ISO 11925-2: Reaction to Fire Tests. Ignitability of building products subjected to direct impingement of flame - Part 2: Single-flame source test. (ISO 11925-2: 2010). Bratislava : Slovak institute of technical normalization, 2011.

[7] FANFAROVA, A.: Methodology for Testing the Fire Retardants and Retardant Modifications of Materials - Reaction to Fire Tests. Internal document with suggestion of enact as STN, Zilina : Department of Fire Engineering, 2014. Verified by: Stefan Galla, managing director of The Fire-fighting, technical and expertise institute of The Ministry of Interior seat in Bratislava, Slovak Republic. 